\title{
Investigation Of Stress Level And Parenting Style Among Parents Of Children Diagnosed As Attention Deficit And Hyperactivity In Iran
}

\author{
Mahnoush Teymouri, Ezgi Ulu \\ Near East University, Iran
}

\begin{abstract}
Attention deficit and hyperactivity disorder (ADHD) is one of the most common psychiatric disorder among children. In this time the role of the family can be important because some negative behaviors of children diagnose ad ADHD can affect their relationship with parents. Aim of study: the goals of this article are to investigate parents of children with ADHD how much they have stress and which type of parenting style they used for their parenting. Method: 50 parents of children with ADHD and 50 parents of healthy children participated in this investigation. Conner's parents rating scale, Robinson parenting style questionnaire, and parenting stress index were used as instruments. Retsult: as expected, parents of children with ADHD show higher stress level than parents of normal children. Also, they use a more permissive or authoritarian parenting style. As a suggestion, clinicians should be careful about the stress parents of children with ADHD may experience and psycho-education given to the parents is important.
\end{abstract}

Keywords: ADHD, Parents, Stress, Parenting Style, parent-child relationship 


\section{3-05 September $2021 \quad$ Prague, Czech Republic}

\section{Introduction}

It is common for parents to be surprised by their children's behavior, wondering how they have learned some actions. It seems that they have no control on their children's behavior and actions. Mostly, they start blaming themselves for what their children show and take all responsibilities on their shoulders. Getting tired of the exhausting situation, they sometimes stop their effort to control it and just leave it. They start normalizing their children's behavior, hoping that it will get better by the time they start going to school or growing. However, this is not what happens in reality; most of the children are unable to cooperate with other students and teachers. Therefore, parents realize that wouldn't get better on it and their children are in need of help, attention, and protection.

this research want to explore the stress level in parents of children with ADHD, and also to find out which type of parenting style they use in interaction with their children. Our hypothesis suggests that the stress level of parents of children with ADHD is more than parents of healthy children. A higher level of stress may cause parents to use more authoritarian or uninvolved parenting style to educate their children. The goals of this study are to compare the stress level and parenting style of parents of children with ADHD with parents of children without ADHD.

Attention Deficit Hyperactivity Disorder (ADHD) is one of the common mental (Nigg, 2001) and neurodevelopmental disorders. ADHD is defined by inattention, disorganization, hyperactivity, and impulsivity (American Psychiatric Association (APA), 2013). By DSM-V (APA, 2013) prevalence of ADHD in most cultures is about $5 \%$ in children. In addition, Faraone, Sergeant, Gillberg \& Biederman (2003)reported that up to 1 in 20 children are diagnosed by ADHD in the USA. The report of Kosari, Keyhani, hemayat-Talab \&Arab-Ameri (2013) is the prevalence of ADHD in Iran nearly to $10 \%$ or $20 \%$. However, the rate of this disorder is higher for boys than girls (Reid \& Shields, 2010).

Darling(1999) defined parenting is included some complex activity, and many specific behaviors can influence on outcomes of children. In parenting, there are two important elements: parenting responsiveness and parenting demands. Parenting responsiveness refers to parental warmth and support. It also refers to the extent of how parents foster individually, selfregulation, self-assertion, and how cooperative with children's special needs and demands. By Baumrind (1991)four category of parenting style including: permissive, authoritative, authoritarian, and uninvolved. Baumrind (1966)addressed the authoritative parent, try to direct children activity in a rational, issue-oriented way. Although the authoritarian parent attempts to control and shape the children behavior with a set standard of conduct.

L.Jones (2001) defines stress as a source of negative conditions and thought experienced by all people of all ages. Miller et al.(1985) explain that the source of stress is in our lives and changes in our lifestyles, orientations, and behaviors. The physical and psychological reaction that happens in our body is because of mismanaged stress. Oxington (2005) explains stress is a physical reaction to an undesirable and unpleasant situation. Also, stress can be short-term 


\section{3-05 September $2021 \quad$ Prague, Czech Republic}

(acute) or long-term (chronic). Acute or short-term stress is a reaction to an immediate or real threat. Chronic or long-term stress involves a situation that is not short.

Lang et.al(2014) explain many methods, including drug therapy and behavioral therapy, or a combination of both, is used to treat ADHD. Bird (2017)Explains one of the important treatments of ADHD is drug therapy by using some medications such as Ritalin. However, the parent-child relationship is one of the important parameters of drug efficacy in ADHD. In this sense, there are two kinds of parenting style that affect children behavior; authoritative and authoritarian parenting. They can affect the emotional and behavioral development of children (Lifford, Harold, \& Thapar, 2008).

Johnston and Mesh(2001) in a literature review explain parents of children with ADHD in all situations have stress, especially in mothers of preschool children. Also, they explain parents of younger children have more stress than parents of older children, therefore, this stress can disturb the parent-child relationship. In this position mothers of ADHD children give more command, less reward and less interactive.

in a qualitative study, Peters \& Jackson (2009) explain the mother's experience of parenting a child with ADHD. They interview with 11 mothers' volunteers who have children with ADHD. After transcribing and coding the data; the result show mothering of children with ADHD is stressful and demanding that need more patient. Also, they feel more isolated from socialization.

Alizadeh, Applequist, Coolidge (2007)search about parental self-confidence, parents' style and punishment. Their sample includes 125 families of 65 students diagnosed with ADHD and 60 students without it as a control group in elementary school in Tehran, Iran. They asked teachers to complete Conner's' Teacher Rating Scale of behavioral problems associated with ADHD and asked parents to complete Parenting Style and Dimensions Questionnaire (PSDQ) (that is a measure examine all parenting style) (Kimble, 2014). and Conner's' Parent Rating Scales. The result of these three questionnaires showed that the parents of children with ADHD were significantly less self-confident. Their result showed that there was no significant difference between fathers and mothers of children with ADHD in the level of self-confidence, but mothers showed more warmth and involvement in both the group of ADHD and the control group of children without ADHD. In addition, fathers of ADHD children use more punishment than mothers.

Finzi-Dottan et al.(2011)argue that parents of children with ADHD think parenting is like more threating and so boring. In their study, 151 parents participated the study, including 71 parents of children with ADHD and 80 parents of children without ADHD as a control group. The result shows parents of children with ADHD they think parenthood is more threat than parents without children with ADHD. Also, their competence was less than the control group (children without ADHD). In addition, parents think daily work with children with ADHD is hard, and they report to feel more unhappy and dissatisfied in their parenting. 
Yousefia et al.(2011)conduct a study in Mashhad, Iran where they compared parenting stress and parenting style among mothers of ADHD children and mothers of normal children. Their sample was 50 mothers of ADHD children who were selected from child psychiatry extra-specialized clinic and 80 mothers of normal children who were selected by the method of stepwise cluster sampling. They find a significant relationship between authoritative and authoritarian styles. However, there is no significant difference between both groups of mothers in permissive parenting styles. Their findings indicate that parenting stress level can affect parenting styles.

Teymouri \& Yousefi (2008) argue that most of the parents of children with ADHD use an authoritarian parenting style. The sample of this investigation includes 50 parents of children with ADHD, 5-12 years old, who identify by psychologist and 80 parents of normal children. They used Baumrind parenting style scale. It is found that the authoritative parenting style is used more by parents of normal children than parents of children with ADHD. In addition, in the permissive parenting style, both groups were at the same level. Moreover, they understand to have a child with ADHD may effect on which parenting style parent will choose.

In a study about "comparing parenting style of children with ADHD and normal children", the researcher used 75 parents of children with ADHD as participates and 75 parents of healthy children as a control group in Zahedan, Iran. Also, they used Baumrind's parenting style questionnaire and analyze the data with SPSS. The results of this study show, permissive parenting style in parents of children with ADHD was lower than the control group. Although, in authoritarian parenting style control group has a lower score than parents of children with ADHD, and in the authoritative parenting style there is no significant between two groups. Also, the study show age, gender of children and parents' education can effect on parenting style (Moghaddam, Assareh, Heidaripoor, Eslami Rad, \& Pishjoo, 2013)

Alizadeh and Andries (2002)talked about the interaction of parenting style and ADHD in Iranian parents. Their participates were 250 parents of elementary school (children between 7 11) of Tehran, Iran, 130 parents (mother: 65 and farther: 65) of children with ADHD and 120 parents (mother: 60 and father: 60) of children without ADHD. They used Conner's Teachers rating scales (CTRS) for teachers and Conner's Parents rating scales (CPRS). Also, they gave the parenting style and dimensions questionnaire (PSDQ) of Robinson to parents. Thus, they find there is a relationship between authoritative and authoritarian parenting style in parents of children with ADHD. It shows when the family has a child with ADHD it possible parents show more authoritarian than authoritative. In addition, they find parents of children with ADHD they don't use the same parenting style for boys and girls.

Dortaj \& Mohammadi (2010) in their study argue about family function in children with ADHD. Their participates include 75 parents of children 7-15 years with ADHD and 75 Parents without ADHD as a control group in Tabriz, Iran. In this study, they use Family assessment device questionnaire (FAD). The result of the study show, the average score of parents with ADHD in "problem-solving, communication, roles, affective responsiveness, behavioral 
control, affective involvement and general functioning" was higher than parents without ADHD.

Munoz-Silva \& Urbano (2016) in another study try to explain parenting style and child ADHD severity and also, parenting style and comorbid behavior problems. They ask 68 parents of children 6-11 years who diagnosed as ADHD as participate. Researcher use criticismrejecting scale, indulgent education style scale, behavior problems scale in the strengths and difficulties questionnaire, and Conner's parent scale. The results of this study show, there is a correlation between child ADHD severity and permissive-indulgent. In addition, a strong correlation in child behavior problem with criticism-rejecting.

In an investigation with parenting stress among families of children with ADHD hypothesis, the researcher used 87 boys and 17 girls with age 49 to 145 months and mothers age with 23 to 48 as participates. First, they interview with families to get information's about the children diagnostic, then used the parenting stress index (PSI) of Abidin. The results of this study show parent and child characteristics have a large number and are important in family stress. Also, the oppositional behavior and difficulty of ADHD can affect stress. At all, it means families with ADHD children have more stress than families who they have children without ADHD (Anastopoulos, Guevremont, Shelton, \& DuPaul, 1992).

Gupta (2007)explain about parenting stress in parents with ADHD children. In this investigation, the researcher used the parenting stress index (PSI) of Abidin. Researcher compares the stress level of parents with ADHD children $(\mathrm{N}=28)$, DD children $(\mathrm{N}=50)$ and HIV children $(\mathrm{N}=46)$. Parents of children with ADHD who they were participates in this investigation reported the highest level of stress for inattention, adaptability and demandingness domain. also, attachment score was higher in children with ADHD.

In an investigation in Israel, the researcher argued about two hypotheses as, first being as a parent of children with ADHD would be related to lower marital satisfaction, lower parental self-efficacy, and higher parenting stress and second parenting stress level and parental selfefficacy can intercede to the relationship between ADHD child and marital satisfaction. the researcher asked 198 mothers or fathers to participate in their study and 182 of them accept as participates, include 63 parents of children with ADHD and 119 parents of children without ADHD. They used parental self-efficacy questionnaire, marital adjustment test (MAT), and parental stress scale (PSS). Thus, results show this investigation confirm both hypotheses that researcher predict. Also, parents with ADHD children have more individual stress experience which leads to decreasing parental self-efficacy and less marital satisfaction. (Ben-Naim, Gill, Laslo-Roth, \& Einav, 2018)

In another study, the researcher examines parenting stress among mothers of children with ADHD. Their participates were include 126 mothers of girls and boys on 6-17 years. They used parenting stress index (until 11 years old), stress index for parents of adolescence (12+ years old), Conner's parent rate scale, the impact of social life scale, the impact of marriage 
scale (which made by Donenberg and baker, 1993), perceived social support. The results of this study show there is a positive correlated between parental stress and children ADHD severity, and with mother's perception of children on marriage and social life. Also, the negative correlation in the mother's perception of social supporting(Muñoz-Silva, Garcia, Urbano, \& Márquez, 2017).

\section{Method}

\section{Participants}

Among non-probability sampling methods, the purposive sampling method is used. families who have children with ADHD are taken in this study. The population was including 70 parents of children with ADHD who were diagnosed by a psychiatrist in the Irana-Mental Clinic in Tehran, Iran. Among them, a total of 50 parents of children with ADHD and 50 parents of normal children who were volunteers randomly filled out the scale as a control group.

\section{Instruments}

\section{Socio-economic form}

demography form asks parents about the gender and age of their child and how old was their child when show ADHD symptoms. Also, it asks the marital status of parents, education level, and work of both parents, mother, and father.

\section{Conner's Parents Rate Scale- Revised (CPR-R)}

Conner's rating scales which was made by Keith Conner's. There are two versions of Conner's scale, parents scale, and teacher scale. Here we used the Persian version of CPR-R with 0.85 validity(Alizadeh, 2005). It isincluding26 questions that completely fucose on Attention Deficit and Hyperactivity in child and adolescent. It means with this questionnaire psychiatrists identify that children have any singe of ADHD or not. Also, it shows which type of ADHD (lack of attention, hyperactivity, or both of them) children have.

\section{Parenting Stress Index (PSI)}

This questionnaire which made by Abidin (1990) includes 120 items in two areas of childhood (47 items) and parents (54 items), and stress of life (19 items). Subscales in child domain includes: distractibility/hyperactivity (DI), reinforces parent (RE), demandingness (DE), mood (MO), acceptability (AC); and in parent domain includes: competence (CO), isolation (IS), attachment (AT), health (HE), role restriction (RO), depression (DP), and spouse/parenting partner relationship (SP). The base of this questionnaire wants to explain the importance of stress in the parent-child relationship. Also, explain this stress may come from children behavior, parent's personality, or parenting role. reliability of this scale for all of the domains is 0.96. Dadsetan, Azghandi, Hasan-abadi (2007)explore the validity of this questionnaire in Persian version 0.88 and after 10 days 0.94 .

\section{Parenting Style- Dimension Questionnaire (PSDQ)}




\section{3-05 September $2021 \quad$ Prague, Czech Republic}

Parenting style dimension questionnaire (PSDQ) which was made by Robinson and it includes 30 questions. It surveys which type of parenting style that parents use. It has three subscales; permissive, authoritative, authoritarian. In this investigation, we used the Persian version of parenting style scale with 0.72 for the reliability of this version which translated by Alizadeh. In detail reliability of this scale for permissive parenting is 0.69 , authoritative parenting 0.73, and authoritarian 0.77(Bahrami, Bagherpour, Fathi, \& Ahmadi, 2009).

\section{Result}

\section{Table 1.}

Multivariate Analysis of Variance (MONOVA) for Conner's Parents Rate

\begin{tabular}{|c|c|c|c|c|c|c|}
\hline Dependent Variable & Group & Mean & Standard Deviation & $\mathrm{F}$ & $\mathrm{P}$ & Partial $\eta^{2}$ \\
\hline \multirow{2}{*}{ Low attention - Memory problem } & ADHD & 9.36 & 2.27 & \multirow{2}{*}{43.70} & \multirow{2}{*}{$0.001^{* *}$} & \multirow{2}{*}{0.31} \\
\hline & Normal & 6.18 & 2.54 & & & \\
\hline \multirow{2}{*}{ Restlessness - hyperactivity } & ADHD & 10.16 & 2.34 & \multirow{2}{*}{50.05} & \multirow{2}{*}{$0.001^{* *}$} & \multirow{2}{*}{0.34} \\
\hline & Normal & 7.08 & 2.00 & & & \\
\hline \multirow{2}{*}{ Emotional instability -impulsiveness } & ADHD & 9.88 & 2.66 & \multirow{2}{*}{26.76} & \multirow{2}{*}{$0.001 * *$} & \multirow{2}{*}{0.21} \\
\hline & Normal & 7.14 & 2.63 & & & \\
\hline \multirow{2}{*}{$\begin{array}{l}\text { Problems with the general impression } \\
\text { of yourself }\end{array}$} & ADHD & 9.72 & 2.73 & \multirow{2}{*}{23.16} & \multirow{2}{*}{$0.001 * *$} & \multirow{2}{*}{0.19} \\
\hline & Normal & 7.14 & 2.63 & & & \\
\hline \multirow{2}{*}{ Hyperactivity index - Low attention } & ADHD & 10.72 & 2.76 & \multirow{2}{*}{43.97} & \multirow{2}{*}{$0.001^{* *}$} & \multirow{2}{*}{0.31} \\
\hline & Normal & 7.14 & 2.63 & & & \\
\hline \multirow{2}{*}{ low memory-memory problems } & ADHD & 10.22 & 2.39 & \multirow{2}{*}{52.09} & \multirow{2}{*}{$0.001 * *$} & \multirow{2}{*}{0.35} \\
\hline & Normal & 6.68 & 2.51 & & & \\
\hline
\end{tabular}

The results of Table 1 show that the difference between ADHD and Normal children groups is significant in all behavioral problems $(\mathrm{P}<0.01)$. Comparison of the means shows that children with ADHD have low attention-memory problems, restlessness-hyperactivity, emotional-impulsivity instability, problems with their overall imagination, low-attentionhyperactivity index, low memory-memory problems, they have a higher mean than normal. Based on the above, the first hypothesis of the present study is confirmed. This means that ADHD and Normal children have different behavioral problems and ADHD children have more behavioral problems. The size of the effect of group membership on the difference between the groups (Partial $\left.\eta^{2}\right)$ varies from 0.19 to 0.35 .

\section{Table 2.}

Multivariate Analysis of Variance (MONOVA) for Parenting Stress Indexes

\begin{tabular}{lllllll}
\hline Dependent Variable & Group & Mean & Standard Deviation & F & P & Partial $\eta^{2}$ \\
\hline \multirow{2}{*}{ Compromise } & ADHD & 24.78 & 3.05 & 29.02 & $0.001 * *$ & 0.23 \\
& Normal & 21.40 & 3.23 & & & \\
Acceptability & ADHD & 21.66 & 2.90 & 1.22 & 0.27 & 0.01 \\
& Normal & 21.00 & 3.06 & & & \\
demandingness & ADHD & 24.66 & 2.94 & 20.23 & $0.001 * *$ & 0.17 \\
\multirow{2}{*}{ Mood } & Normal & 22.04 & 2.89 & 0.24 & 0.63 & 0.01
\end{tabular}




\begin{tabular}{|c|c|c|c|c|c|c|}
\hline \multirow{3}{*}{ distractibility/hyperactivity } & Normal & 10.00 & 2.88 & \multirow{3}{*}{24.64} & \multirow{3}{*}{$0.001 * *$} & \multirow{3}{*}{0.20} \\
\hline & ADHD & 19.76 & 2.97 & & & \\
\hline & Normal & 16.84 & 2.92 & & & \\
\hline \multirow{2}{*}{ reinforces parent } & ADHD & 20.20 & 3.10 & \multirow{2}{*}{20.19} & \multirow{2}{*}{$0.001 * *$} & \multirow{2}{*}{0.17} \\
\hline & Normal & 17.50 & 2.91 & & & \\
\hline \multirow{2}{*}{ depression } & ADHD & 27.02 & 3.56 & \multirow{2}{*}{11.81} & \multirow{2}{*}{$0.001 * *$} & \multirow{2}{*}{0.11} \\
\hline & Normal & 24.68 & 3.24 & & & \\
\hline \multirow{2}{*}{ attachment } & ADHD & 17.66 & 2.94 & \multirow{2}{*}{1.13} & \multirow{2}{*}{0.29} & \multirow{2}{*}{0.01} \\
\hline & Normal & 17.04 & 2.89 & & & \\
\hline \multirow{2}{*}{ role restriction } & ADHD & 19.98 & 4.10 & \multirow{2}{*}{0.57} & \multirow{2}{*}{0.45} & \multirow{2}{*}{0.01} \\
\hline & Normal & 19.42 & 3.29 & & & \\
\hline \multirow{2}{*}{ competence } & ADHD & 40.30 & 5.19 & \multirow{2}{*}{0.22} & \multirow{2}{*}{0.64} & \multirow{2}{*}{0.01} \\
\hline & Normal & 39.80 & 5.50 & & & \\
\hline \multirow{2}{*}{ isolation } & ADHD & 19.98 & 2.63 & \multirow{2}{*}{7.44} & \multirow{2}{*}{$0.01^{*}$} & \multirow{2}{*}{0.07} \\
\hline & Normal & 18.70 & 2.02 & & & \\
\hline \multirow{2}{*}{$\begin{array}{l}\text { spouse/parenting, } \\
\text { relationship }\end{array}$} & ADHD & 22.02 & 2.63 & \multirow{2}{*}{2.16} & \multirow{2}{*}{0.14} & \multirow{2}{*}{0.02} \\
\hline & Normal & 21.30 & 2.25 & & & \\
\hline \multirow{2}{*}{ health } & ADHD & 17.04 & 2.22 & \multirow{2}{*}{9.00} & \multirow{2}{*}{$0.001 * *$} & \multirow{2}{*}{0.08} \\
\hline & Normal & 15.58 & 2.63 & & & \\
\hline
\end{tabular}

The results of Table 2 indicate that the difference between ADHD and Normal children in adolescence and creation in the realm of childhood and in attachment, role limits, sense of competence, and relationships with the spouse in the parents' domain are not significant $(\mathrm{P}>$ 0.05). Differences are found in other sources of parenting stress $(\mathrm{P}<0.01)$. Comparison of the meanings shows that ADHD children have a higher mean in parental stress than normal ones. Based on what has been mentioned, part of the second hypothesis of the present study is confirmed. This means that there is a difference between ADHD and Normal children in terms of compromise, exaggerated, neglected and overweight, empowerment, depression, social isolation, and parental health, and parents of ADHD children are more stressed. The size of the effect of group membership on the difference between the groups (Partial $\left.\eta^{2}\right)$ varies from 0.07 to 0.23 .

\section{Table 3.}

Multivariate Analysis of Variance (MONOVA) for Parenting Style Dimensions

\begin{tabular}{lllllll}
\hline Dependent Variable & Group & Mean & Standard Deviation & F & P & Partial $\eta^{2}$ \\
\hline \multirow{2}{*}{ Authoritarian } & & & & & & \\
& ADHD & 37.58 & 4.31 & 4.20 & $0.04^{*}$ & 0.04 \\
\multirow{2}{*}{ Permissive } & Normal & 35.96 & 3.57 & & & \\
& ADHD & 17.84 & 3.31 & 6.05 & $0.02^{*}$ & 0.6 \\
\multirow{2}{*}{ Authoritative } & Normal & 16.22 & 3.28 & & & \\
& ADHD & 42.56 & 7.49 & \multirow{2}{*}{16.24} & $0.001^{* *}$ & 0.14 \\
\hline
\end{tabular}

$* \mathrm{p} \leq 0.05 \quad * * \mathrm{p} \leq 0.001$

The results of Table 3 indicate that the difference between ADHD and Normal children in parenting styles is significant $(\mathrm{P}<0.05)$. The comparison of meanings shows that ADHD children have a higher mean in authoritarian and permissive parenting than the Normal group. 
In authoritative parenting, parents of Normal children have higher meanings. Based on what has been mentioned, the third hypothesis of the present study is confirmed. This means that there is a difference between the parents of ADHD and Normal children in parenting styles and that the parents of ADHD children have a higher average in authoritarian and permissive. The size of the effect of group membership on the difference between the groups (Partial $\eta^{2}$ ) varies from 0.04 to 0.14 .

\section{Discussion}

This study, investigated parenting style and stress level of parents among children with ADHD. It means we explore parents of children with ADHD most used what type of parenting style and how much they have stress in their parenting style and arising children with ADHD. The Results of this study shows There is a difference between the behavioral problems of children with ADHD and normal. also, there is a difference between the parents' tension between ADHD and normal children. In addition, there is a difference between parenting styles of ADHD and normal children. In this position, with such a similar view there are Many studies with the same result that can explain our results. in this research, we try to find studies who work on parenting style or stress level separately or both of them together on families with ADHD. American psychiatric association (2013) explain children with ADHD will show more inattention, hyperactivity, and compulsivity. Also, they cannot finish their task or sitting on their seat and, will show these sign for six months. So, normal children, they don't have these symptoms or it is less than six months. As for recommendations, it will be good if the researcher can investigate the information level of the family about ADHD. Also, it will be good to get more assistance from fathers as participates in the investigation because the characters and parenting style most of the time is different between fathers and mothers. On the other hands, clinicians first can check the parent's information about ADHD. It will be good if parents have not enough information, psychiatrists explain for them. The other thing is, psychiatrists, can do some therapy or skills as family therapy, stress management, or parenting skill and after that check parents stress level or parenting style. Unfortunately, there is something important that we couldn't explain about that in this investigation. Social vision sometimes can effect on parenting style and stress level. So, in the future study, it will be good if we measured the influence of social support on parenting style of stress level.

\section{References}

Abidin, R. R. (1990). Parenting Stress Index (PSI). Pediatric Psychology Press, 100. Retrieved November 30, 2018, from https://www.parinc.com/products/pkey/333

Alizadeh, H. (2005). Theoretical explanation of attention deficit / hyperactivity disorder: pattern Behavioral inhibition and self-control nature. Research on Exceptional Children, 17(3), 323-348. 
Alizadeh, H., Applequist, K. F., \& Coolidge, F. L. (2007). Parental self-confidence, parenting styles, and corporal punishment in families of ADHD children in Iran. Child Abuse \& Neglect, 31(5), 567-572.

Alizadeh, H., \& Andries, C. (2002). Interaction of Parenting Styles and Attention Deficit Hyperactivity Disorder in Iranian Parents. Child \& Family Behavior, 24(3), 37-52.

Anastopoulos, A. D., Guevremont, D. C., Shelton, T. L., \& DuPaul, G. J. (1992). Parenting Stress Among Families of Children with Attention Deficit Hyperactivity Disorder. Journal of Abnormal Child Psychology, 20(5), 503-520.

American Psychiatric Association. (2013). Diyagnostic and Statistical Manual of mental disorder (5th ed ed.). Arlington, VA: American Psychiatric Publishing.

Bahrami, H., Bagherpour, S., Fathi, A., \& Ahmadi, A. A. (2009). Study of relationship between parenting patterns and mental health and educational achievement of children. Journal of Psychology \& Education, 38(4), 87-100.

Baumrind, D. (1991). The Influence of Parenting Style on Adolescent Competence and Substance Use. The Journal of Early Adolescence, 11(1), 56-95.

Baumrind, D. (1966). Effects of Authoritative Parental Control on Child Behavior. Child Development, 37(4), 887-907.

Ben-Naim, S., Gill, N., Laslo-Roth, R., \& Einav, M. (2018). Parental Stress and Parental Self-Efficacy as Mediators of the Association Between Children's ADHD and Marital Satisfaction. Journal of attention disorders, 1-11.

Bird, P. (2017). Treatment of ADHD. Patent and Trademark Office. Retrieved May 20, 2018, from https://patentimages.storage.googleapis.com/20/a1/c9/8e5a408b46bbff/US9649297.pd $\mathrm{f}$

Darling, N. (1999). Parenting Style and Its Correlates. ERIC Development Team, 1-7. Retrieved October 10, 2018, from https://files.eric.ed.gov/fulltext/ED427896.pdf

Dadsetan, P., Azghandi, A. A., \& Hassanabadi, H. R. (2007). Parenting Stress and General health: A research about parenting stress and general health in nurses and housewives with preschool children. Journal of Iranian psychologists(7), 171-184.

Dortaj, F., \& Mohammadi, A. (2010). Family Functioning in 7-15 year old Children with and without ADHD in Tabriz City. Journal of Family Research, 6(2), 211-226.

Faraone, S. V., Sergeant, J., Gillberg, C., \& Biederman, J. (2003). The worldwide prevalence of ADHD: is it an American condition? World Psychiatry, 2(2), 104-113.

Finzi-Dottan, R., Triwitz, Y. S., \& Golubchik, P. (2011). Predictors of stress-related growth in parents of children with ADHD. Research in Developmental Disabilities, 32(2), 510-519. 
Gupta, V. B. (2007). Comparison of Parenting Stress in Different Developmental Disabilities. Journal of Developmental and Physical Disabilities, 19(4), 417-425.

Johnston, C., \& Mash, E. J. (2001). Families of Children With AttentionDeficit/Hyperactivity Disorder: Review and Recommendations for Future Research. Clinical Child and Family Psychology Review, 4(3), 183-207.

Kosari, S., Keyhani, F., Hemayat Talab, R., \& Arab Ameri, A. (2013). Effect of a Selected Physical Activity Program on The Development of Motor Skills in Attention Deficit/Hyperactivity Disorder(ADHD) and Autism (HFA) Children. Development and Motor Learning(10), 45-60.

L.Jones, T. (2001). Definition of Stress. In J. J. Robert-MacCOMB, Eating disorders in women and children: Prevention, stress management, and treatment. (pp. 89-100). New York: CRC Press.

Lange, K. M., Makulska-Gertruda, E., Hauser, J., Reissmann, A., Kaunzinger, I., Tucha, L., . .. Lange, K. W. (2014). Yoga and the Therapy of Children with Attention Deficit Hyperactivity Disorder. Yoga \& Physical Therapy, 4(3), 1-4.

Lifford, K. J., Harold, G. T., \& Thapar, A. (2008). Parent-Child Relationships and ADHD Symptoms: A Longitudinal Analysis. Journal of Abnormal Child Psychology, 36(2), 285-296.

Miller, L. H., Ross, R., \& Cohen, S. I. (1985). Stress, Cutting it Down to Size. Sydney: George Barber.

Moghaddam, M. F., Assareh , M., Heidaripoor, A., Eslami Rad, R., \& Pishjoo, M. (2013). the Study Comparing Parenting Styles of Children with ADHD and Normal Children . Archives of Psychiatry and Psychotherapy, 15(4), 45-49.

Muñoz-Silva, A., \& Urbano, R. L. (2016). Child ADHD Severity, Behavior Problems and Parenting Styles. Ann Psychiatry Ment Health, 4(3), 1066.

Nigg, J. T. (2001). Is ADHD a Disinhibitory Disorder? Psychological Bulletin, 127(5), 571 598.

Oxington, K. V. (2005). Stress and Health (New Research). New york: Nova.

Peters, K., \& Jackson, D. (2009). Mothers' experiences of parenting a child with attention deficit hyperactivity disorder. Journal of Advanced Nursing, 65(1), 62-71.

Reid, K., \& Shields, M. (2010). Boys and Behaviour: Alternative Strategies That. TEACH Journal of Christian Education, 4(1), 40-45.

Teymouri, s., \& Yousefi, s. (2008). Comparing Parenting Style Between Parent of ADHD Children and Parent of Normal Children. National Conference on Psychology and its Application in Society (pp. 1-13). Shiraz, Iran: SID. Retrieved April 26, 2019, from https://www.sid.ir/Fa/Seminar/ViewPaper.aspx?ID=5812

Theule, J., Wiener, J., Rogers, M. A., \& Marton, I. (2011). Predicting Parenting Stress in Families of Children with ADHD:Parent and Contextual Factors. J Child Fam Stud, 20, 640-647. 
Yousefia, S., SoltaniFar, A., \& Abdolahian, E. (2011). Parenting stress and parenting styles in mothers of ADHD with mothers of normal children. Procedia - Social and Behavioral Sciences, 30, 1666-1671. 